\title{
Kahramanmaraş İlinde Süt Sığırı İşletmelerinde Bulunan Merkezi Sağım Sistemlerinin Mevcut Durumunun ve Yapısal Özelliklerinin Belirlenmesi
}

\author{
Serpil GENÇOĞLAN \\ Kahramanmaraş Sütçü İmam Üniversitesi, Ziraat Fakültesi, Biyosistem Mühendisliği Bölümü, \\ Kahramanmaraş \\ (Sorumlu yazar e-mail: sgencoglan@ksu.edu.tr)
}

Geliş Tarihi : 12.06.2017

Kabul Tarihi :23.07.2017

\begin{abstract}
ÖZET: Bu çalışma, Kahramanmaraş ilindeki süt sığırı işletmelerindeki merkezi sağım sistemlerinin mevcut durumlarını ve yapısal özelliklerini ortaya koymak amacıyla 2016 yllında anket metoduyla yürütülmüștür. İșletmelerdeki ortalama hayvan sayısı 293, sağmal hayvan sayısı ise 136 adettir. İşletmelerde birden fazla süt sığırı ırkı olup en fazla yetiştirilen ırk \%89.7 oranıyla Holstein'dır. Bunu \%51.7 oranıla Simental, \%17.2 oranıla Siyah Alaca 1rkı takip etmektedir. İşletmelerin \%65.5'inde merkezi sağım sistemi, sağım odası, bekleme salonu ve sağım çukuru bulunmaktadır. İșletmelerin \%17.2'si paralel, \% 48.3'ü balık kılçı̆̆ı sistemini kullanıp durakların \%5'i tek, \%95'i çift sıralıdır. Sağım odalarında ortalama 12 durak olup durak alanı $3 \mathrm{~m}^{21}$ dir. Bekleme salonunda her bir hayvan ortalama $13 \mathrm{dk}$ bekletilmektedir. İsletmelerin \%82.8'inde sağım öncesi her hayvana ortalama $2 \mathrm{dk}$ hazırlık yapılmaktadır. Sağım çukuru boyutları ise ortalama 2.5x10x1 m'dir. İşletmelerin \%64.3'ünde süt akış hızını ölçer ve \%70.4'ünde pulsatör (nabız ölçer) aleti bulunmamaktadır. Merkezi sağım sistemlerinde genellikle 2 adet sağımcı çalışmaktadır. Sonuç olarak Kahramanmaraş İlinde, merkezi sağım sistemleri hızlı bir șekilde yaygınlaşmaktadır. İşletmelerin genelinde jeneratör, süt akış hızı ölçen alet ile pulsatör gibi yardımcı ekipman kullanımında eksiklikler görülmüştür.
\end{abstract}

Anahtar kelimeler: Otomatik sağım sistemleri, sağım odası tipleri, balık kılçığı, paralel sağım sistemi

\section{Determination of the Current Situation and Structural Properties of Central Milking Systems in Dairy Cow Enterprises in Kahramanmaraş}

\begin{abstract}
This study was carried out to reveal the current status and structural properties of milking systems in the dairy cow enterprises in Kahramanmaras province. The questionnaires of the enterprises were made in 2016 and evaluated. In the enterprises, there are average 293 cows and average 136 dairy cows. There is more than one dairy cow in the enterprises and the highest breed is Holstein with $89.7 \%$. This is followed by Simental with $51.7 \%$ and Siyah-Alaca race with $17.2 \%$. In the $65.5 \%$ of the enterprises, there are central milking system, milking room, waiting room and milking pit. In the $17.2 \%$ of these are abreast stall milking system, $48.3 \%$ herringbone stall. In these both systems, $5 \%$ of stalls are one row and $95 \%$ of two rows stall. There are average 12 stalls in the milking rooms and the average area of stall is $3 \mathrm{~m}^{2}$. Each dairy cow is hold for average 13 minutes. In $82.8 \%$ of the enterprises, each dairy cow preparation before milking is taken an average of $2 \mathrm{~min}$. The dimensions of milking pit are average $2.5 \times 10 \times 1 \mathrm{~m}$. In the $64.3 \%$ of the enterprises, there is no milk flow rate meter and $70.4 \%$ no a pulsators. In milking systems, usually 2 operators are employed. As a result, the central milking systems are spreading rapidly in Kahramanmraş province. There are no the use of electricity generators, milk flow rate meter and pulsators in all enterprises.
\end{abstract}

Keywords: Automatic milking system, milking parlour types, herringbone, side by side milking system

\section{GİRIS}

Merkezi etkinliğini arttırarak hayvanlara kolay, hızl, hijyenik ve sağlıklı bir sağım işlemi sunar. Bu sayede daha az insan işgücü ile kısa zamanda çok sayıda hayvan sağılabilir. Süt sığırcılığında sağım, işletme içerisinde yapılan işlerin büyük bir kısmını ve toplam işgücünün $\% 50$ 'den fazlasını oluşturmaktadır. Bir üreticinin alması gereken kararlardan en zor ve karmaşık olanı merkezi sağım sisteminin seçimidir. Bunun nedeni servis ömürlerinin 15-20 yıl olmasından dolayı işletmelerin planlanmasinda önemli bir yer tutmasıdır (Thomas, 1994; Smith vd., 2005; Rodenburg, 2012).

Merkezi sağım sistemi tasarımında öncellikle sağım yeri tipi belirlenmelidir. Sağım yerinin tipine etki eden faktörler ise sürü büyüklüğü, işletmenin ekonomik gücü, sağım odasının büyüklügü̈, düzenlenme şekli, yerleşim durumu, hayvan trafiği, sağım işçiliği, sağım iş programı ve mekanizasyon düzeyidir (Öztürk, 2003). Seçilecek sistemin, işçilik kalitesini arttırması ve kolaylaştırması yanında kurulumu kolay, maliyeti düşük, bakımı ucuz ve güvenli olmalıdır (Kumlu, 2012).

Süt verimini arttırmak ve yüksek kaliteli süt üretmek için üreticilerin etkili bir sağım sistemi yönetimine ihtiyacı vardır (Smith vd., 2005). Sağım yerlerinin tasarımında işletmedeki tüm hayvanların 60-90 dakikada sağılabilmesi göz önünde tutulmalıdır. Ancak sağmal sığır sayısının 100 baştan fazla olması durumunda bu geçerli değildir. Çünkü sağım süresi bu değerlerin üzerine çıktığ 1 zaman sağımcının etkinliği hızla azalmaktadır. Kültür ırkı süt sağım süresi ortalama 4-6 dakika arasında değişirken yüksek verimli sığırların sağım süresi düşük verimli sığıllara göre oldukça fazladır (Olgun, 2011).

İşletmelerde, merkezi süt sağım sistemlerinin seçiminde sağım odası boyutları, maliyet ve hayvan 
Kahramanmaraş İlinde Süt Sığırı İşletmelerinde Bulunan Merkezi Sağım Sistemlerinin Mevcut Durumunun ve Yapısal Özelliklerinin Belirlenmesi

sayısı dikkate alınmaktadır. Sağım yerlerinin tasarımını belirleyen en önemli faktör, işletmedeki mevcut ve gelecekteki sağmal hayvan sayısıdır (Y1ld1z, 2013).

Son yıllarda yarı-açık serbest duraklı ahırların yaygınlaşmasıyla birlikte sağım odası sistemleri ön plana çıkmıştır. Süt sığırı işletmelerinde ardışık, balık kılçı̆̆ı, paralel, poligon-trigon ve döner platform merkezi sağım sistemleri kullanılmaktadır (Kumlu, 2008).

Kırmacı ve Pınar (2009), Samsun yöresinde büyükbaş hayvan yetiştiriciliği yapılan işletmelerde mekanizasyon durumunu saptamak amaciyla yaptıkları çalışmada işletmelerin \%68.3'ünde tek başlıklı, \%21.9'unda çift başlıklı süt sağım makinesi, \%9.8'inde $2 \times 6$ balık kılçığı sağım sisteminin olduğunu tespit etmişlerdir.

Tilki vd. (2013), Kars ve ilçelerinde hayvanların büyük bir kısmının (\%81.07) elle sağıldığı tespit etmişlerdir. Bunu seyyar süt sağım makineleri (\%15.29) takip etmektedir. Sağım ünitelerinin kullanımı ise \%3.64'dür. Bölgede sağım üniteleri yeni kullanılmaya başlanmıştır.

Kumlu (2008)'de ardışık, balık kılçı̆̆ı, paralel ve döner sağım sistemleri; sığırları izleme, sığır konforu, işçilik kalitesi, çalışma şevki, çalışma yolları, sağıma alma, alan ihtiyacı, donanım kurulumu için yer, durak başına sağım kapasitesi ve fiyat kıstasları dikkate alınarak yapılan karşılaştırmada, her bir kıstas 5 puan alınarak yapılan değerlendirmede toplam 100 puan üzerinden balık kılçığı 78 , ardışık ve paralel 66 , döner sağım sistemi ise 62 puan alarak işletmecilerin en çok balık kılçı̆̆ı sisteminden memnun olduğunu göstermiştir.

Otomatik sağım sisteminin geliştirilmesi, 1950'li yıllara rastlamaktadır (Akman, 2003). Çeşitli ülkelerde artan işgücü masrafları, sağım işleminde otomasyona geçilmesinin başlica sebeplerinden biri olmuştur. Ticari işletmelerde ilk otomatik sağım sistemi Kuzeybatı Avrupa'da uygulanmıştır. Otomatik sağım sistemlerinin bu ülkelerde geliştirilmeye başlamasına, aile tipi işletmeler ve işgücü pahalılığg neden olmuştur. İşletmecileri, hem süt fiyatlarındaki düşme eğilimi hem de işgücü, arazi, bina ve mekanizasyon masraflarındaki artma zorlayıcı olmuştur (De Koning vd., 2001, Meijering, 2004).

En uygun sağım sisteminin hangisi olacağ hakkında yıllardır yapılan çalışmalar ve uygulamalar sürmektedir. Eskiden beri kullanılagelen balık kılçığı sisteminden, hayvanların süt sağım sisteminden hızlı çıkış ihtiyacı arttıkça paralel sisteme geçiş olmuştur. Son yılarda ise, $\mathrm{ABD}$ ve $\mathrm{AB}$ 'de paralel sistemlerin bazı olumsuzlukları olduğu görülerek tekrar balık kılçığı sistemine, eğer sürü çok büyükse döner sağım sistemine dönüş tercih edilmeye başlanılmıştır (Gülsoy, 2014).
Kahramanmaraş ili, Türkiye'nin Akdeniz Bölgesi ile Doğu ve Güney Doğu Anadolu Bölgelerinin geçiş alanında bulunur. İlde Kahramanmaraş, Elbistan ve Göksun Ovaları ile yüksek su kaynağı potansiyeli bulunmaktadır. Kahramanmaraş, verimli geniş üretim alanları, akarsu potansiyeli ve uygun iklim özellikleri ile bitkisel ve hayvansal üretimde önemli bir yer tutmaktadır. Gıda, Tarım ve Hayvancılık İl Müdürlüğü kayıtlarına göre, İl genelinde yaklaşık 170.000 sığır ve 75.000 süt sığırı vardır (Anonim, 2015a).

Merkezi (sabit) süt sağım sistemi sayısı, 2016 yılı verilerine göre Türkiye genelinde 10.057, Kahramanmaraş ilinde ise 45 adettir (Anonim, 2017). Ancak bu veriler Kahramanmaraş Gıda, Tarım ve Hayvancılık İl Müdürlüğü kayıtlarına uyumlu değildir.

Türkiye'de farklı yörelerde süt sığırcılığı işletmelerinin mevcut durumu ve yapısal özelliklerinin belirlenmesine yönelik birçok çalışma yapılmıştır. $\mathrm{Bu}$ tip çalışmaların belirli aralıklarla tekrarlanması, alandaki verilerin güncellenmesi, sektördeki mevcut durumun tespiti, zaman içerisindeki değişimlerinin takip edilebilmesi ve sorunlara çözümler getirilebilmesi yanında geleceğe yönelik gerçekçi planlamaların yapılabilmesi için de önem arz etmektedir (Şeker vd., 2012). İldeki büyük süt sığırı işletmelerinde kullanılan süt sağım sistemlerinin yaygınlığını ve sorunlarını daha detaylı şekilde ortaya koymanın yararlı olacağı düşünülmektedir. $\mathrm{Bu}$ tip çalışmalar sayesinde ilgili alandaki problemlerin doğru olarak tanımlanması sonucu gerekli çözümler bulunabilmektedir.

Yukarıda verilen nedenlerle bu çalışmanın amacı, Kahramanmaraş ilindeki merkezi süt sağım sistemlerinin mevcut durumunu ve yapisal özelliklerini belirlemektir.

\section{MATERYAL VE METOD}

Kahramanmaraş Gıda Tarım ve Hayvancılık Müdürlügünden alınan bilgilere göre ilde mevcut 29 işletme bulunmaktadır. Bu işletmelerin tümüyle tam sayım yöntemi kullanılarak anketler yapılmıştır. Anketlerden elde edilen birincil veriler tanımlayıcı analizler uygulanmıştır.

Anonim (2017)'e göre Kahramanmaraş ilindeki 2016 yılı süt sağım sistemi sayısı 45 adettir. Ancak Kahramanmaraş Gıda Tarım ve Hayvancılık Müdürlüğünden alınan bilgilere göre ilde mevcut 29 işletmede sağım sistemi bulunmaktadır. Sayılardaki bu farklılığın nedeni işletmecilerin iş tecrübesinin olmamasından dolayı işletmelerini birkaç yıl içinde kapatmak zorunda kalmasıdır.

Kahramanmaraş İl ve ilçelerinde süt sığırı yetiştiriciliği yapan işletme sayıları Çizelge 1'de verilmiştir. İşletmelerin \%37.9'u Elbistan ilçesinde bulunurken, \%13.8'i Dulkadiroğlu, \%13.8'i Göksun, 
\%13.8'i Pazarckk, \%10.3'ü Onikişubat, \%3.4'ü Afşin, \%3.4'ü Andırın ve \%3.4'ü Türkoğlu olmak üzere ilde toplam 29 işletme bulunmaktadır.

Çizelge 1. İşletmelerin ilçeler bazında dağılımı

\begin{tabular}{|l|c|c|}
\hline İlçeler & Frekans & \% \\
\hline Onikişubat & 3 & 10.3 \\
\hline Dulkadiroğlu & 4 & 13.8 \\
\hline Göksun & 4 & 13.8 \\
\hline Elbistan & 11 & 37.9 \\
\hline Afşin & 1 & 3.4 \\
\hline Pazarcık & 4 & 13.8 \\
\hline Andırın & 1 & 3.4 \\
\hline Türkoğlu & 1 & 3.4 \\
\hline Toplam & $\mathbf{2 9}$ & $\mathbf{1 0 0 . 0}$ \\
\hline
\end{tabular}

\section{BULGULAR VE TARTIŞMA}

Süt Sığırcılığı Yapan İşletme Sahiplerinin Demografik Özellikleri

Kahramanmaraş'ta süt sı̆̆ırcılığı yapan işletme sahipleri ile yapılan anket sonuçlarına göre cinsiyet durumlarının hepsinin erkek, yaşlarının ise minimum 25 , maksimum 68 ve ortalama 43 yaşın üzerinde olduğu tespit edilmiştir. Eğitim durumlarının ise \%46.4'ü ilköğretim, \%21.5'ü lise, \%32.1'inin ise üniversite mezunu olduğu belirlenmiştir. İş tecrübesinin ise \%10.7'sinin yetersiz, \%25'inin orta, $\%$ 64.3'ü iyi düzeyde olduğu tespit edilmiştir.

\section{Süt Sığırcılığı Yapan İşletmelerin Genel Özellikleri}

Anket verilerine göre İldeki işletmeler 19912015 yılları arasında faaliyete başlamışlardır. Özellikle 2000'li yıllardan sonra işletmelerin açıldı ̆̆ belirlenmiştir. İşletmelerin \%96.6's1 özel, \%3.4'ü üniversite kuruluşu, \%86.2'si mülkiyet sahibi, \%6.9'u kiracı ve \%6.9'u ortaklara sahiptir. İşletmeler toplam hayvan sayısını en fazla 2000, sağmal hayvan sayısını da en fazla 1000 adete arttırmayı istemektedir.

İşletmelerde genellikle birden fazla hayvan 1 rk1 bulunmaktadır. Bu 1rklardan Holstein, işletmelerin $\% 89.7$ 'sinde varken \%10.3'ünde bulunmamaktadır. Simental \%51.7'sinde, Siyah Alaca \%17.2'sinde, Kırmızı Alaca \%6.9'unda, Jersey \%3.4'ünde, bu işletmelerin \%17.2'sinde ise yukarıdaki irklardan daha farklı ırklar bulunmaktadır. İşletmelerdeki sağmal sığır ırkları homojen olmadığından irklar arasında süt sağım süreleri farklılığından dolayı sağımcının işi zorlaşmakta ve iş verimliliği düşmektedir (Kumlu, 2008). İşletmelerdeki hayvan sayıs 1 maksimum 1900, minimum 25 adet olup ortalama 293'dir. Sağmal hayvan sayısı ise maksimum 1050, minimum 2 ve ortalama 136 adettir. Gelecek y1llarda işletmelerin \%92.9'u, sağmal hayvan sayısını arttırmayı planlanmaktadır. İşletmelerin \%65.5'in de sağım odası vardır. Sağım odası bulunan işletmelerin \%17.2'sinde paralel, \%48.3'ünde balık kılçığı sağım sistemi kullanılırken; ardışık, poligon ve dönerli sağım sistemi tercih edilmemiştir. Yapılan çalışmada tercih edilen balık kılçığı sağım sistemi Tilki vd. (2013) ile Gülsoy (2014) verdiği sonuçlarla uyum sağlamaktadır.

Sı ğırların sağım yerine gruplar halinde alındı ̆̆ sistemlerden biri paralel diğeri balık kılçığıdır. Balık kılçığı sağım sistemi, hem küçük ve hem de büyük işletmeler için uygundur. En büyük avantajı, küçük bir alanda çok sayıda sığırın sağılmasıdır. Yandan sağımın bütün avantajlarını ve duraklarda sığırların memelerini eğilmeden daha düzgün incelemesine olanak sağlar (Gülsoy, 2014; Anonim, 2014). Mekanizasyona uygundur. Pnömatik kontrollü göğüs bariyerleri, sığırların sıraya dizilmesini kolaylaştırır. $\mathrm{Bu}$ sistemde iş verimliliği artar, sağımcılar stressiz çalışır ve sığırlara gerekli yardım için az zaman harcadığından dolayı diğer çiftlik işleri ve ailesiyle daha çok vakit geçirebilir (Slater, 1991; Kumlu, 2012; Anonim, 2014; Anonim, 2015b). Dezavantaj1, sığırların yavaş sağılmasından dolayı sırada çok beklemesi ve sağımcı sı̆̆ırların yanında durduğu zaman tekmelenme riskinin fazla olmasıdır (Anonim, 2015c-d).

Paralel sağım sisteminde, sağım durakları genellikle sağımcı platformuna dik konumda yan yana yerleştirilir. Sığırlar sağım duraklarına genellikle yandan girerler ve durağı yandan ya da ön taraftan terk ederler. $\mathrm{Bu}$ sistemde yürüme mesafesi 60-75 cm olup bir balık kılçı̆̆ 1 sisteminden daha kısadır (Olgun, 2011; Reinemann, 2003). Balık kılçığı sisteminden hayvanların hızlı çıkışı gerektikçe paralel sağım sistemine geçiş olmuştur. En büyük avantajı küçük bir alanda çok sayıda sığırın sağımına imkan vermesidir. Bu sistem, en az 500 baş sağmal kapasitesine sahip büyük işletmeler için önerilmektedir (Anonim, 2015b; Kumlu, 2008; Kumlu, 2012). Dezavantajı ise sağımcının sığırı tanıması, memeyi tam olarak görebilmesi ve memenin temizliğini yapması zordur. Sağım başlıkları genellikle sığırların arka bacakları arasından uzanılarak takıldığından dolayı hem sağım başlıklarını takmak zor hem de her an dışkıya maruz kalmak olasılığı fazladır (Reinemann, 2003). Paralel sağımın bu dezavantajlarından dolayı balık kılçığı sistemi dünyada ve ülkemizde yaygın olarak kullanılmaktadır (Gülsoy, 2014).

Süt sağım sistemi, işletmelerin \%79.3'ünde işletme sahibinin isteğiyle, \%13.8'inde mühendis ve $\% 6.9$ 'unda ise veteriner önerisi ile kurulmuştur. 


\section{Süt Sığırcılığı Yapan İșletmelerin Yapısı ile İlgili Genel Bilgiler}

İşletmelerin hepsi kullandıkları sağım sistemini özel kuruluşlardan temin etmiştir. İşletmelerin kuruluş tarihindeki maliyetleri 30.000-20.000.000 TL arasında, ortalama 2.112 192 TL'dir. Büyük yatırım yapılan bu işletmeler, TKDK (Tarım ve Kırsal Kalkınmayı Destekleme Kurumu) ve AB (Avrupa Birliği) tarafından desteklenmiştir. Büyük çoğunluğu TKDK tarafindan desteklenen işletmeler bu desteklerin \%48.3'ünü ahır yapımında, \%51.7'sini işlemede kullanılan alet/ekipmanda ve \%13.8'sinide canlı hayvan alımında kullanmışlardır. İşletmelerin tamamı merkezi süt sağım sistem kurulumu için destek almışlardır.

İşletme içinde arazi varlığ 1 maksimum 1000, minimum 3 ve ortalama 100 dönümün üzerindedir. İşletmelerin \%85.7'si yem bitkisi ekerken, \%14.3'ü dışarıdan temin etmektedir. Yem bitkisi eken işletmeler arasında maksimum ekim alanı 1500, ortalama ise 199 dönümdür. İşletmelerin 19'unun mimari projesi vardır. Projelerin sadece \%48.4'ü mühendislere çizdirilmiştir.

İşletme yerinin seçimine \%6.9'u pazara yakınlık, \%13.8'i ulaşım imkanları, \%3.4'ü üniversiteye yakınlık, \%20.7'si üretim alanına yakınlık, \%55.2'sinde ise hepsinin içerdiği faktörler etkili olmuştur. İşletmelerin şehir merkezine yakınlığ 1 en az 2 , en fazla 38 ve ortalama ise 13.7 km'dir.

\section{Sağım Sistemlerinin Genel Özellikleri}

İlde süt sığırcılığı yapan işletmelerin \% 65.5'inde merkezi sağım sistemi bulunmaktadır. İşletmelerin \%16.7'sinde sağım odası alanı 0-50 $\mathrm{m}^{2}$, $\% 22.2$ 'sinde $51-100 \mathrm{~m}^{2}$, \%22.2'sinde 101-200 $\mathrm{m}^{2}$, $\% 16.7$ 'sinde 201-300 m², \%11.1'inde 301-36 m² arasinda, \% 5.55'inde $600 \mathrm{~m}^{2}, \% 5.55$ 'inde ise 1000 $\mathrm{m}^{21}$ dir. Ortalama sağım odalarının alanı $232 \mathrm{~m}^{21}$ dir.

Sağım odalarında maksimum durak sayısı 48, ortalama ise 12 durak bulunmaktadır. Durakların $\% 5$ 'i tek, \%95'i çift sıralıdır. İşletmedeki süt hattının konumuna göre $\% 75^{\prime}$ i alttan, \% 15 'i üstten ve $\% 10$ 'unda da ortadan süt hattı kullanılmaktadır.

Sağım odası bulunan işletmelerin \%75'inde sağım çukuru vardır. Sağım çukurunun ortalama en, boy ve derinliği sirasıyla $2.5,10$ ve 1 m'dir. İşletmelerin \%65.5'i sağım öncesinde bekleme salonuna sahipken \% 34.5'inde bekleme salonu yoktur. Bekleme salonu olan işletmelerde bekleme alanı ortalama $142 \mathrm{~m}^{2}$, maksimum ise $1000 \mathrm{~m}^{21} \mathrm{dir}$. Her hayvan bekleme salonunda ortalama $13 \mathrm{dk}$, maksimum ise $30 \mathrm{dk}$ beklemektedir. İşletmelerin \%82.8'inde sağım öncesi hazırlık yapılmakta ve her hayvan için bu süre ortalama $2 \mathrm{dk}$ 'dır.

Her bir hayvan ortalama $7.7 \mathrm{dk}$ içinde sağılmaktadır. Olgun (2011)'e göre kültür ırklarının sağım süresi 4-6 dk'dır. Bulunan sonuçlar, Olgun (2011)'de verdiği değerden yüksektir. İşletmelerin \% 89.7'sinde günde 2, \%10.3'ünde ise 3 defa sağım yapılmaktadır. Sağım işlemi günün farklı zamanlarında yapılmaktadır. Sabah sağım işlemine en erken saat 4.00 'de en geçte 8.30 'da başlanılmaktadır. Öğle saatindeki sağımı günlük üç defa sağım yapan işletmeler kullanmaktadır. Bu sağıma işletmelerin \%33.33'ü saat 11.00'de, $\% 33.33$ 'ü 14.00 'de ve \%33.33'ü de saat 15.00 'de başlamaktadır. Akşam sağım işlemine en erken saat 15.00 'de en geçte 22.00 'de başlanılmaktadır. İşletmelerin \%42.9'unda sığırlar, ortalama saat 17.00 'de sağılmaktadır. Sağım süresi, 100 baş sağmal hayvana sahip işletmelerde ortalama 1 saattir. Bu ortalama sağım süresi, sağmal hayvan sayısı 100-150 arasından ise 1.5-2.5 saat, 250 baş ve yukarısında ise 4-6 saat arasında değişmektedir. Sağım süresi işletmelerin sahip olduğu hayvan sayısına, sağım sistemine, hazırlık aşamasına ve sağımcı sayısına göre değişmektedir. $\mathrm{Bu}$ süre işletmelerden az 30 , en fazla 720 ve ortalama $100 \mathrm{dk}$ 'dir. Sağmal hayvan sayısı arttıkça sağım için harcanan zaman da artmaktadır.

Sağım esnasında işletmelerin \%89.7'sinde yemleme yapılmazken \%10.3'ünde sağmal hayvan sayısı az olduğundan dolayı yemleme yapılmaktadır.

Sağım ünitesinde çalışan sağımcı sayısı işletmelerin $\% 28$ 'inde 1, \%44'ünde 2, \%20'sinde 3, $\% 4$ 'ünde 5 ve $\% 4$ 'ünde ise 7 adettir. İşletmeler genel olarak 2 adet sağımcı kullanmaktadır.

\section{Yardımcı Ekipmanlar}

İşletmelerin \%70.4'ünde süt soğutma tank1 bulunmaktadır. Bunların sayıları işletmelerin $\% 41.1$ 'inde $1, \% 13.8$ 'inde 2 ve $\% 10.3$ 'ünde ise 3 adettir. İşletmelerdeki ortalama süt tankının uzunluğu, genişliği ve yüksekliği sırasıyla 3.2, 2.9 ve 3.6 m'dir.

Sağımda kullanılan süt akış hızı ölçer aleti, işletmelerin \%64.3'ünde, pulsatör aleti ise \% 70.4'ü bulunmamaktadır. Kullanılan pulsatör aletlerinin \%36.4'ü pnömatik, \%63.4'ü ise elektroniktir.

Elektrik enerjisi, işletmelerin \%48.1'inde şehir şebekesinden, \%51.9'unda ise hem şehir şebekesinden hem de jeneratörden almaktadır. Aynı zamanda elektrik kesintisine karşı işletmelerin \%70.4'ü jeneratör bulundurmaktadır. Jeneratörlerin maksimum kapasitesi 240, ortalama kapasitesi ise 74 kWh'tir.

Sonuç olarak, ilk yatırım maliyeti yüksek olan süt sağım sistemlerinin hem işçiliği azaltarak iş randımanını arttırması hem de hayvanlara kolay, hızlı, hijyenik ve sağlıklı bir sağım işlemi sunması nedeniyle doğru seçimi, kullanılması, bakımı ve hijyeni önemlidir. 


\section{KAYNAKLAR}

Akman, N., 2003. Pratik Sığır Yetiștiriciliği, II. Basım, 35-48 s. Türk Ziraat Mühendisleri Birliği Vakfı Yayını, Ankara.

Anonim, 2014. Milking Line. Finding The Perfect Milking Parlor Has Never Been Easier, Via Mattei, 4-Loc. Gariga- 29027 Podenzano (PC)-Italy.

Anonim 2015a. Kahramanmaraș Gıda, Tarım ve Hayvancılık İl Müdürlüğü, Hayvan Sağlığı ve Yetiştiriciliği Şube Müdürlüğü Kayıtları, Kahramanmaraş.

Anonim, 2015b.

http://www.csok.cz/prilohyarchiv/1040/BAUER_CATTLE_ EN.pdf-

Anonim, 2015c. http://www.agri-ergonomics.eu/downloads/PDF/ Summary/milking_cows_LR . pdf-Saat :12.05 (30.12.2015).

Anonim, 2015d.

http://www.publish.csiro.au/?act=view file $\&$ file $\mathrm{id}=97806$ 43107403_Chapter 13.pdf-Saat :12.05- (30.12.2015).

Anonim, 2017. Tuik.

http://www.tuik.gov.tr/VeriBilgi.do?alt_id=1006 Saat: 11(21.07.2017).

De Koning, K., Vorst, V. and Meijering, A., 2001. Automatic Milking Experience and Development in Europe. http://www.milkproduction.com Saat :9.00 - (20.07.2017).

Gülsoy, A., 2014. Sağım Teknikleri, Süt Sı̆̆ırcılığında Hijyen, Sağım ve Sağım Teknikleri, T.C. Gıda Tarım ve Hayvancılık Bakanlığı Dergisi, Ankara, 28 s.

Kırmacı, N. ve Pınar, Y., 2009. Samsun yöresinde büyükbaş hayvan yetiștiriciliğinin mekanizasyon durumu. 25. Tarımsal Mekanizasyon Ulusal Kongresi Bildiri Kitabı, 59$63 \mathrm{~s}$

Kumlu, S., 2008. Kaliteli ve Yüksek Süt Verimi İçin Sağım Teknikleri. AB Sınır Ötesi İşbirliği Çerçevesinde Bulgaristan Burgas Ruen Süt Üreticileri Birliği ile Kırklareli Ahır Hijyeni ve Sağım Teknikleri Paneli, Kırıkkale.
Kumlu, S., 2012. Süt verimi ve kalitesi. AB ve Türkiye'de Danışmanlık Sistemleri ve Süt Sığırı İşletmelerin Yönetimi Dergisi, Cilt:1, 388 s, Aydın.

Meijering, A., 2004. The International Symposium on Automatic Milking. Lelystad, March, 20-24. http://www.automaticmilking.nl/symposium. Saat :10.00(21.07.2017).

Olgun, M., 2011. Tarımsal Yapılar Ders Kitabı 2. Bask1. Ankara Üniversitesi Ziraat Fakültesi Tarımsal Yapılar ve Sulama Bölümü, Yay. No. 1577, 447 s, Ankara.

Reinemann, J., 2003. Milking Research and Instruction Lab., Milking Parlor Types.

Rodenburg, J., 2012. Milking Systems, Selection, Cost and Implications. Dairy Facility Design for Improved Cow Comfort, Health and Longevity, Ramada Plaza, Abbotsford, BC, November 14-15.

Slater, K., 1991. The Principles of Dairy Farming. 11th. Edition. $359 \mathrm{~s}$.

Smith, J., Dhuyvetter, K.C, Vanbaale, M.J, Armstrong, D.V, Harner, J., 2005. Managing the milking parlor: An economic consideration of profilability. NMC. Annual Meeting Proceedings. 166-180 p.

Şeker, İ., Tasalı, H., Güler, H., 2012. Muş ilinde sığır yetiştiriciliği yapılan işletmelerin yapısal özellikleri. Fırat Üniv. Sağ. Bil. Vet. Dergisi, 26(1): 9-16.

Thomas, C., 1994. Operations and Economic Models For Large Milking Parlors. 31 st. Annual Dairly Production Conference.

Tilki, M., Sarı, M., Aydın, E., Işık, S., Aksoy, A.R., 2013. Kars ili sığır işletmelerinde barınakların mevcut durumu ve yetiştirici talepleri: I. Mevcut Durum. Kafkas Univ. Fak. Derg. 19(1):109-116.

Öztürk, T., 2003. Tarımsal Yapılar. Ondokuz Mayıs Üniversitesi, Ziraat Fakültesi, Ders Kitabı No: 49, Samsun, 296 s.

Yıldız, B., 2013. Cankırı İli Süt Sı̆̆ırı Barınaklarının Yapısal Özellikleri ve Yeni Barınak Modellerinin Geliştirilmesi, Yüksek Lisans Tezi, 95, Konya. 